\title{
Love Me for a Reason: An Auto- ethnographic Account of Boyzone Fandom
}

Simone Driessen

Erasmus University Rotterdam

driessen@eshcc.eur.nl

\section{Bethan Jones}

University of Huddersfield

bethanvjones@hotmail.com

\begin{abstract}
Fan scholars such as Matt Hills have argued that fannish interests can become relevant and irrelevant at different times during a fan's life. Combining insights from popular music and fan studies, in this article we use an auto-ethnographic approach to examine our changing levels of interest in Boyzone. Both of us encountered the Irish boy band at different times in our lives, and both of us experienced our fandom in different ways. In relation to the band's fandom, Boyzone's music can be considered a technology of "self" (DeNora 2000): a vehicle that people use to work through their biographies by recalling particular emotions and memories. We theorize this engagement with our fan object both by considering Cornel Sandvoss' notion that media fandom is a partial extension of the teenage self, and Rebecca William's concept of post-object fandom. Using our two experiences as a case study, we show how dormant music fandom can develop in different ways for fans in different circumstances.
\end{abstract}

KEYWORDS: music fandom, boy bands, Boyzone, post-object fandom, post-youth 


\section{Introduction}

Fans, according to Duffett (2013: 18), are people with a high "positive emotional conviction about someone or something famous". Moreover, Cavicchi (1998) states that becoming a fan is about becoming converted, which entails a high influence and involvement of the object of fandom on everyday life. However, moments of "re-conversion", such as reunions, have gained little attention in popular music and fan studies. As Harrington and Bielby (2010: 434) remark, accounts of "fans' sustained engagement with media objects over time and transformations of fandom in later life" are scarce. However, a (reunited) music fandom offers an emblematic ground to review these transformations. Tim Wise (2012: 119) states that a reunion is particularly yearned for by pop fandoms, as "pop music fandom is often about more than just attraction to the sounds". This force of music to go beyond sounds is visible in DeNora's definition of music, as she considers it a "technology for spinning the apparently continuous tale of who one is" (2000: 63). Furthermore, this transformative power of music also helps to expose and structure a sense of self (DeNora 2000).

Boyzone was founded in 1994 as a dance act of four. Soon after, in an attempt to capitalize on the success of Take That, the Irish act turned into a boy band comprising five members: Ronan Keating, Stephen Gately, Shane Lynch, Keith Duffy and Mikey Graham. Between 1994 and 1999 Boyzone released three albums and several singles that entered the Top 5 of the UK charts. In 1999, the band decided to split. However, in 2007, after a seven-year hiatus, "the Boyz" announced they were back - for the annual BBC fundraiser Children in Need. The band went on tour again, and performed at sold-out venues across the United Kingdom and Ireland. In 2009, one of the singers, Stephen Gately, died unexpectedly of an undiagnosed heart condition - a moment of grief for the band, and for the fans. Nevertheless, the band continued as a four-piece and released its sixth studio album in 2014. New opportunities have been created by these recent phases of the band's career for original fans to return to the object of their fandom.

In this auto-ethnographic account we review our changing levels of involvement in Boyzone fandom. Drawing on our own backgrounds as researchers in fan and popular music studies, we wish to examine the affordances (see DeNora 2000) that Boyzone and their music have offered us. By taking an auto-ethnographic approach, we are able to map the changes that we underwent and perceived over time. In doing so, we "self-consciously explore the interplay of the introspective" self and external world (Ellis 2004: 38). We want to make our personal experience an illustration of "facets of cultural experience, and ... make characteristics of a culture familiar to insiders and outsiders" (Ellis et al. 2011: 9). Consequently, we wish to share our narratives as an indicator of a larger phenomenon; namely, an exploration of what happens to popular music fandoms over time, and across geographic boundaries (see Chin and Morimoto 2013). Since an auto-ethnography "begins with a personal story" (Wall 2008: 39), in conjunction with relevant academic literature (see Wall 2008) we guide the reader through our personal, chronological fan stories. Our retrospective accounts have enabled us to reflect on the transition from teenage "Boyzone fandom" into our current (adult) fandom (see Ellis et al. 2011). 
Throughout the article, we examine the transformational character of our fannish identities. ${ }^{1}$ After discussing previous research into on-going fandom, our two narratives are presented. Simone reflects on how life course transitions influenced her fandom. Bethan reviews how the death of Stephen Gately formed a turning point in her fan identity. Last, we outline different levels of engagement, and suggest a framework for defining the (dis)continuation of music fandom explored in our auto-ethnographies.

\section{Lifelong fandom}

To explore extended involvement with our fan object, we first turn to examples of research discussing previous work on extended fandom. ${ }^{2}$ There is an emerging trend in the field of fan studies, subcultural studies and popular music studies, to map lifelong involvement with a media object or media fandom. Harrington, Bielby and Bardo (2011: 571) note that aging and changes in the life course, and the changing role of media fandom, "are dual processes that inform and shape one another". Moreover, what they see is that "adult fans hold themselves and others accountable to age norms", which leads to shame and stigma, and make fan pleasures (after youth) more difficult to experience (Harrington, Bielby and Bardo 2011: 584). Hodkinson (2013) notices a similar development in youth cultures: staying involved in a certain (music) scene after youth is argued to be an indicator of not wanting to grow up. He argues, however, that long-term participation in a youth culture is a way for individuals to "negotiate their way through different stages of the life course" (2013: 19). These participants negotiate their attachment alongside other commitments, such as family or work. Bennett (2006), in his study on aging punks, has made this insight: he argues that the punks might have toned down their looks, but they earned their position, and are now more involved as conveyors of the genre, and consider themselves "forefathers", or critical "overseers" of the scene. Again, they do so due to their reflexive identities, consequently reflecting on their identity.

Stevenson describes how this reflexivity of the fans turns the object of fandom into a "cultural resource, which can be reinterpreted in the context of their changing life situations" (2009: 85). The David Bowie fans he interviewed indicated how Bowie formed a stable force in times of trouble and uncertainty, a spiritual guide, and an example of change, yet providing "comfort from the maelstrom" (Stevenson 2009: 88) of a globalized world. Of interest about Stevenson's work, are the questions he is left with after his study, including how to deal with "our own feelings in the process of research? ... It is not until sometime later that you begin to understand your own response" (2009: 96). When we started writing this auto-ethnography, we had similar questions to Stevenson. As aca-fans we are already acknowledging our fannish interests in our work by positioning ourselves as fans as well as (and alongside) academics (see Hills 2002). ${ }^{3}$ As Stevenson remarks, he is a Bowie fan; this makes doing interviews easier. Yet, while he does discuss his feelings immediately following the interviews, he necessarily leaves unaddressed how the research has affected his long-term identity and practice. In this paper we aim to "to reflect ... the same 
sense of identity and self-understanding" (Wall 2008: 41) that we have in everyday life when we talk about our Boyzone fandom. We aim to go beyond current scholarship by mapping our own feelings as lifelong fans, and reflecting on the ways that our fan object's affordances are "constituted and reconstituted in and through projected courses of action within [our individual] settings" (Anderson and Sharrock 1993:148-9).

Our paper challenges findings from researchers such as Bennett (2006) and Stevenson (2009) that either leave women out, or suggest or assume that they are less expressive about their fandom as they get older. Several female scholars have mapped their fandoms before us. Sue Wise (1984) used her recollections as a teenaged Elvis follower to consider how fans interpreted his image. Laura Vroomen (2002) wrote about mature, female Kate Bush fans and how Bush's music afforded them feelings of empowerment. Additionally, Tonya Anderson (2012) studied adult Duran Duran fans, who reclaim their youth by attending the concerts. Although being aca-fans, they do not discuss their own experiences in detail. Maud Lavin (2015: 1.3) does do so, in her description of her Patti Smith fandom. She used Smith's image, she reveals, "at times in my own autobiographical storytelling to confirm either my own changes or steadfastness". As our auto-ethnography will expose in the upcoming paragraphs, we recognize some of the feelings addressed in previous work. Instead of mapping any participation in a music scene or subculture, or fascination for a female solosinger like Patti Smith, we wish, instead, to consider our path from the "mainstream pop fandom" of our teenage years to adulthood, and thus offer a situated investigation that features two examples of long-term music interest.

\section{Auto-ethnography as method}

As a qualitative research method, auto-ethnography has sometimes been met with scepticism. Wall notes "as auto-ethnography continues to emerge, define itself, and struggle for acceptance, it is important for those working with it reflect on the use of the method and share their experience with others" (2008: 40). Some scholars have gone further and questioned whether auto-ethnography should be a legitimate method of doing research (see Guyotte and Sochaka 2016; Holt 2003). Due to the creation of accounts that use self-disclosed and self-interpreted individual experience expressed through first person writing and reporting as data source, questions emerge such as how to ensure rigor, or verify the evidence. Crawford, however, notes that theorizations of fandom have often "been based on restrictive typologies, rather than considering the process, development and often fluidity of being a contemporary ... fan. ... These also tend to present static models, which fail to recognize the ... temporality of individuals' locations within these communities" (2004: 38). We therefore argue that since our Boyzone fandom has transformed over time, the representation of such changing experience calls for the pursuit of self-reflective narratives. Autobiographical reasoning "helps us appreciate how the transformational event of entering fandom becomes situated in individual life histories" (Harrington 2010: 2.2). We aim, and instruct our readers, however, to consider our personal accounts as broader examinations designed to use our "own experiences to extend understanding of a 
particular discipline or culture" (Holt 2003: 2). Pursuing auto-ethnography, as opposed to autobiography, encourages us to explore and make sense of our individual stories as part of a larger genre that includes similar studies previously written about attachments to television, education, sports, nursing, and adoption. It means that our self-reflexive analysis not only offers an account of the phenomenon investigated (Boyzone fandom), but that "through [discriminating] broader generalization" it may also transcend this to inform contemporary understandings of media fandom (Anderson 2006: 388). For us, writing the autoethnography collaboratively offers "a means to explore culturally significant experiences from multiple perspectives" (Guyotte and Sochaka 2016: 2). In our exploration, we "might include dramatic recall, unusual phrasing, and strong metaphors to invite the reader to 'relive' events with the author" (Holt 2003: 12). Thus, we have followed a rather traditional path in the opening section of this research paper to "facilitate this [auto-ethnographic] analysis" and carefully pave the way (Sturm 2011: 224).

\section{Loving Boyzone for a reason: becoming a fan}

Boyzone carries different meanings for both of us. Growing up in the United Kingdom, Bethan was much closer to the band's roots and spoke the language of the band (English). For Simone, growing up in the Netherlands, Boyzone provided a reason to learn English and consider the dream of going to Dublin to see them live in concert. In this first section, we separately share our "becoming-a-fan" narratives (Cavicchi 1998). In the next, we discuss the transformation of our fandom, and offer three different outlines that describe our current involvement.

\section{a) Bethan - becoming a fan}

I wasn't a "girly girl" when I was a child. I was more interested in reading Hardy Boys books and turning my Sindy house into a livery yard than I was dressing up and playing with makeup; the lift was great for transporting hay bales from the ground floor stable into the kitchen. I was also fed a steady musical diet of Meatloaf, Elton John, Queen, and Genesis, played on tapes in long car rides, with my sister and I singing along in the back. At the age of 10 my dad took us to see Meatloaf live in Cardiff. We - at 10 and 8 - were the youngest fans there, but we knew the words to every song and sang along with Meat, skipping the "naughty" words, which we weren't allowed to say. My mother was in hospital with a slipped disk in her back. I remember telling her the following day, "Mam, he said the F-word!"

When I turned eleven in 1993, I was too young for New Kids on the Block, and it was no surprise that I was not at all interested in Take That. Even though I was broadly content to sit in my room and read with Genesis playing on my cassette player, part of me was vividly aware of my difference. The other girls in my class in school loved boy bands. They swooned over Mark Owen's hair and adored bad boy Robbie Williams. I didn't see what the fuss was about, so I was excluded from playground conversations about the latest single, and for a while tried to become a fan. I put a poster of Take That on my bedroom wall, but I wasn't 
invested in the band. I had no desire to be their fan. Adorno (2001), discussing jitterbug fans, suggests that they aimed to "infect" those around them but this did not work with boy bands and my eleven year old self. As Duffett writes, "Contagion seems impersonal in implying that any individual can be "bitten" by the bug of a fan interest" (2013: 125, emphasis in original). No matter how much the girls in my class talked about Take That, however, their enthusiasm - their fandom - didn't infect me. My plan to become a fan, then, failed, calling to mind Duffett's (2013: 154) point that "[n] obody first consciously plans to become a fan. It is not something achieved by rational design".

I was, then, fandomless - at least in the sense of boy bands. Then Boyzone formed. They were five lads from Dublin; the youngest, Ronan, only six years older than I, and I fell utterly in love. I cannot tell you why, when, or even how it happened. What I can tell you, though, is about the first time I saw "the Boyz" in concert at Newport Leisure centre in 1994. My mother took me, my sister, and my sister's best friend straight from school, and I can still remember the nervous excitement I felt walking through the sports centre (the tang of chlorine from the swimming pool in the air) getting ready to be in the same room as the band. This was, as Cavicchi (1998: 153) notes of Springsteen fans' "becoming-a-fan" narratives, "a milestone in [my life] in which 'everything changed"”; I began to think of myself in terms of being a fan rather than not being a fan. The ticket for that first concert is currently hanging in a frame on the wall in my house, along with the first tour T-shirt I bought (from the Said and Done tour), photos of "the Boyz" from various concerts - including the BZ20 anniversary tour.

\section{b) Simone - becoming a fan}

In 1999, my dad and I drove two hours to Rotterdam. We were early, but the square around Ahoy, the venue, was packed with girls my age. I was twelve at the time, and I had gotten a ticket for the Boyzone concert for my birthday. We were so early we got to see the tour bus arrive - I went nuts. Screaming, running towards the gates, which the bus disappeared through: all I wanted was an autograph! Obviously, I did not get one: the five boys rushed into the venue, but just slow enough to make sure we, the teen fans, got a good look at them, or a smile from them. I sincerely believed that Shane, and even Ronan (my hero) had looked at me. "Don't make yourself tired right now, we've still got to go in", my dad chuckled. He observed the spectacle from a distance, and, when I returned, slightly disappointed, comforted me with those words.

The concert was great: I had tears in my eyes, did not sit down for a minute, and sung along to every song. I was dancing on my seat (literally), and so were others around me. However, we were on a bench far from the stage. Yet, I swear, although I know it is impossible, that during "I Love the Way You Love Me" Ronan waved at me. "He waved at me dad, he looked at me!" I screamed to express my emotions of happiness and excitement, but most of all it gave me a rewarding feeling. I had loved the band already for so long, and this wave was my reward. When we got home, it was the first thing I told my mom.

That concert was their only performance in the Netherlands during their heydays (except for a concert in 1995, which I was too young to visit and happened too far from my home-town). Boyzone did not have many hit-songs in 
the Netherlands. The Backstreet Boys overruled them by far in popularity. In my final year at elementary school nobody liked Boyzone; many girls loved the Backstreet Boys, especially Nick or Brian. Not Ronan or Stephen. Yet, Boyzone made up a huge part of my teenage identity. Sandvoss (2005: 96) proposes we need to consider an object of fandom not (only) "in relation to the self, but as part of the self" (emphasis in the original). When I saw "Love Me for a Reason" (their first hit) on MTV, I fell for the cheerfulness of the song, and for lead singer Ronan. Soon, my whole life revolved around them. I bought all their albums and singles, played their music every day, talked a lot about them, decorated my bedroom with Boyzone posters, and I dreamt of (marrying) Ronan.

I could relate myself to Boyzone's position. In the Netherlands, they held the position of the underdog, in the boyband wave of the late 1990s (Baker 2013). They were not just part of my teenage identity, I also mirrored my own feelings to their popularity, their less favoured position in the album charts. Sandvoss notes, this perception is "... based on the recognition, consciously or unconsciously, of aspects of the self in the external object" (2005: 97). I considered this unique and good, because then there would not be too many fans of the band. I did not belong to the popular cliques at school and I did not like things that were overly popular or "mainstream", because I was not either. As Sandvoss (2005: 96) argues "the object of fandom ... is intrinsically interwoven with our sense of self, with who we are, would like to be, and think we are". I felt like the underdog myself in my teenage years, which only strengthened my fandom of the band.

Through this reflection on my teenage fandom I learned "something new" about myself (Wall 2008: 48). Moreover, I learned to understand my "becominga-fan" process, which is also "intended to help others understand the world of which I speak" (Wall 2008: 48). As the exact milestone (Cavicchi 1998) at which one becomes a fan is often difficult to pinpoint, I did offer an insight in what feelings the band awoke in me, and what practices I committed too.

\section{No Matter What: the transformative phase in our fandom}

After highlighting our milestones (Cavicchi 1998), we also note how these "musically fostered memories ... contain momentum" (DeNora 2000: 66). Both of us have peak (musical) experiences we remember best (see Green 2016). However, in this section we reflect upon how the fandom altered while growing up. Our routes diverged during this phase: Bethan was deeply affected by Stephen's death, which made her return to the fandom, while Simone struggled with (dis)continuing her fandom.

\section{a) Bethan - the transformative phase}

Over the years I've seen "the Boyz" at least twenty times - a fact that most people find surprising given my move towards goth and EBM over the years, and the substantial number of tattoos and piercings I have. I've attended every tour at least once, even during my university years, and as recently as the BZ20 tour in 2013. The only tour I missed was the last tour Stephen Gately ever did - the Better tour in 2009. Stephen was my favourite member of the band. Most of the other fans I 
knew - and there weren't that many - preferred Ronan, and Ronan was always painted as the most popular member of the band in the press. But Stephen was the one for me. I used to daydream about meeting him when I was walking home from school, not wanting to be in a relationship with him but simply being friends. I developed what Horton and Wohl (1956) have referred to as a parasocial relationship with the band, and particularly with Stephen. It is fair to say that Stephen was my first crush and that may, as Anderson (2012: 240) suggests, have "instigated the formation and continuance of [my] fan attachment". Both my sister and I, however, suspected that Stephen might have been gay long before it was revealed that he was. I vividly remember sitting in the optician's in my town, reading an interview Stephen did with Smash Hits! or Just Seventeen in which he refers to a possible partner as "he", before backtracking and saying, "I meant her". ${ }^{4}$ I have no way of finding that interview now, and nothing but my memory to suggest it even existed, but I remember feeling sad that someone I felt such a connection to had to hide who he was in love with. Stephen came out as gay in 1999 after a security guard threatened to expose him in The Sun newspaper. The story that actually emerged was a far more far more sensitive story, in which The Sun allowed Stephen pre-approval and called it "the most moving showbiz interview you will ever read". Craig McLean (2006) writes, in his article "I'm Gay and in a Boy Band" for The Guardian:

A helpline was established for traumatised fans. But the fans weren't traumatised: they were cool and supportive and, if any anything, even more ardent in their love of Boyzone's blue-eyed baby-face. Letters came in by the sack load. Gately was voted Smash Hits' Hero of 1999.

One of those letters was mine. I remember writing that "the best piece of advice I've ever received is to ignore the opinions of those people you don't respect". I said that Stephen's fans respected him and would support him, and I sent it to Stephen care of the fan club. The only other time I've felt compelled to write in to a club or newspaper because of a celebrity was in complaining to the Press Complaints Commission about the article Jan Moir wrote in the Daily Mail ${ }^{2}$ after Stephen died. The article was published on 16 October 2009, implying that Stephen's cause of death was not "natural" and attempting to link this to his sexuality. The PCC received 25,000 complaints about the article, including mine:

I read the article earlier today and found it to be a poorly disguised attack on homosexuality and homosexuals, which could also constitute a hate crime where her direct actions in publishing this have caused a potential increase in homophobia; something clearly against the law in the country. Furthermore, the article also breaches the PCC's Code of Practice ...

The PCC ultimately ruled the article was lawful, but the paper was forced to withdraw adverts by Marks \& Spencer, Nestle, Visit England, Kodak and National Express (Booth 2009). This kind of fan activism is not new to me (I have contributed to many X-Files fundraisers), but in many ways it has been the closest to my heart. ${ }^{6}$ Stephen's death was the first celebrity death that really affected me.

I'd moved back home and was living at my dad's when it happened. I remember walking downstairs, my dad looking up at me and saying, "Stephen's 
died". I was devastated. I cried on and off for days afterwards, joined groups on Facebook and listened to the CDs over and over again. Harju (2015: 2) notes, "Communal sentiments of grief may come up in community forums, such as fan sites. Such dedicated online spaces allow expressions of grief that fall outside our normative realms of acceptable grief or extended public mourning", and the Facebook groups I joined offered me a space to mourn when friends I had offline didn't understand what was wrong, as well as a sense of belonging.

Stephen's death did not renew my fandom - I had always been a fan, even though I missed the Better tour - but I found myself engaging in practices like wearing Boyzone merchandise and listening to their music more following his death. Radford and Bloch (2012: 149) theorized fan reactions to the death of NASCAR driver Dale Earnhardt Sr. through introjection and incorporation; they write: "Following the death of a loved one, an individual also may feel a loss to their extended self (Belk 1988) and consumers try to compensate with the acquisition of material goods (Wicklund and Gollwitzer 1982)".

Incorporation occurs when objects representative of the deceased are used as a means of keeping some part of that person alive. Material objects, places, or activities associated with the deceased become means of enhancing memories.

I didn't buy any material goods following Stephen's death, but I did keep copies of the newspapers that reported his death and his funeral. I also began wearing a silver Boyzone bracelet I'd bought at one of their earlier tours. I hadn't worn the bracelet for years, but I felt a need to demonstrate my fandom - to others possibly, but more fundamentally to myself - following Stephen's death. Stephen's funeral also, however, had particular importance to me as a fan. I watched the funeral - broadcast live on Sky while my dad was out. I was sitting on the settee unable to stop crying, and even seeing photos of "the Boyz" carrying Stephen's coffin in the process of researching this article brought back those feelings of loss. As I have already noted, I kept copies of newspapers from the day of the funeral, but in discussing Stephen's death with a friend who was also a Boyzone fan, I discovered she had taped the funeral. I asked her to send it to me. I've never watched it but I know exactly where the DVD is, and it's an important part of my fandom because it's the loss of one of the people who meant so much to me. I needed to have physical evidence of the funeral, not just the newspaper I've kept from the day, but the actual object. Discussing Michael Jackson's death and the live broadcast of his memorial service, McCurdy (2010: 237) suggests

\footnotetext{
the desire to participate in the live broadcasting of history] may also be attributed to the intimate links forged with celebrities through the consumption of mass media. Thus, it was not enough to simply view the funeral as a media event but, precisely because of these connections, there was a need to participate in it.
}

I would argue, though, that in addition to the participation in the media event, there was - for me at least - a need to adopt other fan practices (and/or rituals) around collecting. Fan collecting is an area to which more attention is being paid, but the collection of objects focussing on or related to grief is yet understudied. 


\section{b) Simone - the transformative phase}

After 1999, Boyzone disappeared off the radar in the Netherlands. During my high school years there was no news, no interviews, no new videos, not even a website or online community to keep up (see Driessen 2015). Boyzone just wasn't there, nor was their music. Their lyrics, about love and loss, were too sappy to afford me to think about the transitions I underwent in that phase of my life.

Their unavailability (see Chin and Morimoto 2013) and the lack of "fitting" music made my fandom go dormant. Nevertheless, Boyzone and I should be closer than before. As a high school student, I should be able to relate to first love and the heartbreaks they sung about, but I did not find consolation in their music anymore. Hills (2002) wrote how he felt a certain fear in relation to his Doctor Who fandom: he reviewed how media fandom is (often) linked to a sense of failing to grow up (see Hodkinson 2013). Yet, he did not leave being a fan behind, he moved onto becoming involved in horror fandom(s). He moved on to a new fandom, transitioned from one "knowing field" to another (Duffett 2013). Although Boyzone became less relevant to me when I got into high school, I did not immediately take up a new fandom. I did not feel a need to "officially" leave the fandom because of my growing older. Their posters stayed on my bedroom walls until I could move rooms in my parents' house, which was in my late teens. I was not ashamed for that part of my identity to remain visible.

Yet, due to their absence in the Dutch media, and growing older, I looked for new music to listen to: At one point, I had a poster of Boyzone, punk rock group the Offspring and rock icon Marilyn Manson hanging next to each other on my bedroom walls. My record collection contained Boyzone, Five, B*witched and Nirvana, the Offspring, and Greenday. Duffett (2013: 158) remarked how a fandom "seems to end through pressures such as gender ideals or notions of appropriate taste". Yet, I never felt ashamed of listening to Boyzone, I just discovered and liked new music (in addition to theirs). In hindsight, I do consider this change in music taste (perhaps more appropriate for a rebellious teenager), and the punk rock records slowly taking over, the starting point for my fandom to go dormant.

When Boyzone announced their reunion in 2007, I turned twenty. Their reunion was never announced in Dutch media, I wasn't aware of it. Nor did I actively look for it, I had other things to spend my time on. I was a student, working side jobs, and involved in the local punk scene. Hodkinson and Bennett (2013) define this life phase as post-youth, a life stage in which you gain new responsibilities and duties (for example working a full-time job, or becoming a mother). For me this meant studying, working to afford the rent, and keeping my own household running. The biggest difference as a post-youth fan is that fan practices change (for example no posters on the wall, but wearing a bracelet of a band). Although I don't own a CD player anymore, I do move Boyzone's albums with me whenever I move house. Sandvoss (2005: 101) remarks that the object of fandom "... is not so much a textual possession ... It is part of the fan's (sense of) self". Occasionally I play their music, as they are too much a part of my teenhood to lose or ignore. Albeit dormant, they are part of my life. If music, as DeNora (2000) argues, is an ongoing story of who one is, Boyzone's music affords me a reflection on who I was. 
By keeping the albums, I believe I stay loyal to the band. Listening occasionally to their music did afford a sense of stability in the changes I went through as a post-youth (see Stevenson 2009), and it taught me to "think about my experience" (Wall 2008: 48) of feeling affection for something/someone. Yet, due to Boyzone's absence in the Dutch media, and my age-graded life transitions that didn't resonate or occur in their music, my fandom went dormant and didn't continue.

\section{Every Day I Love You: our current involvement with the fandom}

In the previous section we described the transformative phase of our fandoms while growing older. For Simone this manifested in a dormant fandom, which, offered her "productive fannish emotions" (Duffett 2013: 163) to reflect upon a particular life phase. Bethan focused on the "peak moment" (Green 2016) of Stephen's death, rather than the band's 2000-2007 hiatus. Next, we review how we currently (still - or no longer) engage in the fandom and how the affordances of our fandom have shifted.

\section{a) Bethan - current practices}

I followed the rest of "the Boyz" more closely after Stephen's death, partly because I was hurting for them and genuinely wanted to know how they were doing, and partly because of the guilt (there's no better way of putting it) that I felt for missing the Better tour. When tickets were released for their Brother tour, in which Stephen played a large part through (and despite) his absence, I was on the ticket website before 9am, determined to get a seat.

Seeing "the Boyz" live for the first time after Stephen died was a strange experience. I expected to see the five of them on stage and kept looking for Stephen. Williams (2011: 266), writing about post-object fandom, discusses it in relation to "the specific moment when a fan object moves from being an ongoing text into a dormant one which yields no new instalments". For Williams, postobject fandom occurs when the TV series ends, but how to define a text with a less secure ending, for example a hiatus, or a return? Duffett's (2013: 162) "knowing field", defined as "a terrain of affect ... bounded by a threshold beyond which one can say, 'Yes, I know that I am a fan'", implies that the knowing field is a state of "conscious" fandom. Yet, we did not know if Boyzone would come back, even while we kept (hope for) crossing the threshold. And (yet) after Stephen's death, the band changed. The name was still the same, four of the original members were still there, but Stephen was missing: the fannish object had fundamentally changed. Fans, including me, thus "refashioned their self-identity to deal with this rupture" (Williams 2011: 274). Boyzone post-2009 became an amended-object, and my fandom of the band, while still of Boyzone, became an amended-object fandom (Jones 2015).

Writing about regenerations in Doctor Who and fan responses to these, Williams (2015) notes that some fans stop watching when the Doctor is replaced. Where I am finding correlations is through the show's "reiteration discourse", where fans are afforded to reassess their identities, due to the impact of the show 
(ibid). This is different for me in relation to Stephen's death and the band continuing. The ending of a TV show is something to prepare for, which helps to "deal with any potential threat to ontological security provided by fan objects" (Williams 2015: 79). Engaging in this reiteration discourse following Stephen's death though, afforded me to process his death with the support of other fans and the amended-object facing me.

Following Stephen's death there was a lot of debate about whether "the Boyz" would continue without him. The band had been working on an album when Stephen died, and the decision was made to release it as a tribute called Brother, with two songs featuring Stephen on vocals. The album was released in March 2010, earlier than planned. I remember going to my local supermarket before work, on the day it was released, listening to it on my commute, and tearing up at Stephen's voice. The album was followed by the Brother tour, which paid tribute to Stephen in 2011. As I've already mentioned, I went to the tour, and seeing the four boys on stage made me immediately look for Stephen. Seeing "the Boyz" live, even eighteen months after Stephen's death, reinforced my sense of them as an amended-object. Stephen was referred to a lot during the evening; his picture featured prominently on the screens backing the stage; fan tributes had been included in the tour programme, the boys told stories about him and their relationships, and in a particularly emotional scene, sat at a table with five chairs, poured five glasses of wine, and toasted Stephen.

The band have released another two albums and continue to tour. BZ2O was their anniversary tour - both a celebration of the twenty years we've had with the band and a reminder of what and who we've lost (individually and collectively). The latest album, Dublin to Detroit, is a concept album which many fans seem to be less keen on, but which we have bought anyway. I no longer have Boyzone posters on my walls and I don't wear band T-shirts anymore, but I have photos of "the Boyz" on my desk at work. Sometimes I still wear my Boyzone bracelet. Seeing them in concert has changed as well. There's a sense of maturity - for them and for us. There's still a lot of screaming, of course (and I refuse to be ashamed of that!), but we've all gone through different experiences, so it feels like somehow we're all more equal.

\section{b) Simone - current practices}

The news about Stephen Gately's death in 2009 came to me via Twitter. Dutch media barely paid attention to it. Luckily, having mastered the English language to a near-native level, and having access to British and American entertainment and news websites (Chin and Morimoto 2013), I could find reports about the accident. I learned that "the Boyz" - to honour Stephen - had taken the same tattoo as him (the Superman logo); that the funeral was a major happening in Ireland; and that Stephen's boyfriend was inconsolable. Due to work or studies I did not watch a broadcast of the funeral, but I later caught up with some clips on YouTube. Stephen's death affected me, but I did not cry, nor did I feel a need to mourn. However, his passing did draw me back to listening and watching some of "the Boyz"' music clips via YouTube.

Although the reason for them to be in the news was sad, I did enjoy hearing about the band. Due to this, I also discovered their "reunion" tour. While I am in 
a social and financial position to attend their tour (in the UK, Ireland or the US), I do not feel a need to do so. Occasionally, I play a video (through YouTube); now, though, this practice is loaded with my own memories that I built up over the years. I consider the music valuable, not as a guilty pleasure or a moment of "reclaimed youth" (Anderson 2012), but as relaxing music that I like to listen to when I am completely stressed out. It affords a sense of comfort (Stevenson 2009), but also a five-minute break from everyday life. Whenever I hear "I Love the Way You Love Me" I still think back to that concert in 1999, seeing those long white coats they wore, and Ronan waving. I think of the teenage friends I no longer hang out with. I think of my dad, whom I dragged along to that concert, and how he is getting older. I think of "the Boyz", who are also older, and dads themselves. Yet, maybe, because I am not yet in this position (of having children or being married), and their bodies have aged differently, I "only" have memories; rather like the music fans interviewed in Stevenson (2009), Bennett, (2006), and Lavin (2015), I haven't felt like I "aged along" with my chosen musicians, and I can't, therefore, project my life onto theirs.

For me, Boyzone's music works in a therapeutic way, similar to how Ellis et al. (2011) state that writing can work. Both Boyzone's lyrics and my memories of the band, help me cope with the tasks and duties I currently face as a post-youth woman. The music affords me an opportunity to (re)connect with different versions of my self: my teenage self, my student self, and my post-youth self. My fan practices may have changed; Boyzone will always be part of my personal identity.

\section{Conclusion}

This research paper stems from a shared interest: we wanted to extend the current field of (semi) autobiographical writing by aca-fans, to take up the "banner of explicit and reflexive self-observation" (Anderson 2006: 375). Our autoethnographic accounts have exposed how our Boyzone fandom "helps us define who we are, what we believe, and influences whom we befriend" (Herrmann 2013: 7). By making our "becoming-a-fan" narratives explicit, we have situated "the personal [in relation] to the cultural, social, and political" (Ellis 2004: xix) and elucidated how we, as teens, "got converted" and gave meaning to feelings of (unreturned) affection. As two women describing their fandom of an all-male band, we have not discussed gender in-depth, as we were not able to shed light on comparable bodily changes or to study how we aged "along" the band (see Lavin 2015; Stevenson 2009). Yet, we did challenge convention (see Hills 2002), by offering an insight into our adult female fandom for a band working in a pop genre (mainstream boy bands) that is often presumed to appeal only to teens and should be outgrown as fans get older (Baker 2013; Duffett 2013; Hodkinson 2013). Remarkably, the different paths taken in our fandom happened in our postyouth life phase, while our band held their hiatus.

Although both of us are white, Western women, growing up in Europe, who were both transitioning from teens to adults occupied with studies and work, our access to Boyzone, their music, and news about them, was very different. Bethan continued her fandom, albeit in a different way than at first, due to Boyzone 
turning into an amended-object for her. The death of Stephen affected her so much that she revived her fandom. Yet, her fandom does not feel the same as before, as the amendment of her object refashioned her fan identity. Simone, meanwhile, did not share the same feelings, due to the lack of media coverage of Stephen's passing in her country of residence. Simone learned through her autoethnography that her bond with Boyzone was (in hindsight) weaker than Bethan's, due to the band not being sufficiently transcultural. Such differences in access might be expected to happen between East and West, or if language-skills formed an issue (see Chin and Morimoto 2013), but they are much less expected between "neighbouring" countries. Future research on accessibility of pop music and fandom is therefore needed. What listening to Boyzone's music did later afford Simone was a break from the everyday and a way to reconnect with, and reflect upon, her previous life phases. Her auto-ethnographic fan account has shown that thinking about one's dormant fandom can become a means of memory-recall. We suggest that these two different affordances - revamping (and acknowledging) a changed object, or reflecting on dormant fandom to expose landmark biographic memories - may provide a conceptual framework for future studies about lifelong fandom. Finally, what writing these accounts has also exposed is the way in which our Boyzone fandom affects our academic work. We have shared our experiences with the band and the fandom personally, at conferences, and on social media. Not only do we position ourselves of aca-fans of the band, but our shared fandom forms part of the connection we have with each other, as friends as well as scholars.

\section{Endnotes}

1 "Fannish" is a term from fan studies meaning "pertaining to fandom" (Duffett 2013: 293).

2 "Fan object" is a phrase from fan studies that means the text or hero (for example, the Beatles) which forms the focus of a fan's passion.

3 "Aca-fan" is a term from media fan studies meaning "an academic who usually teaches in cultural studies, studies fandom, supports the cultural legitimacy of fandom as a social identity and proudly attests to being a fan in his/her own life and work" (Duffett 2013: 289). They are not simply scholars who also have fan passions, but rather fans who use their academic role to support the wider acceptance of fandom.

${ }^{4}$ Smash Hits! was a pop music magazine, published in the UK between 1978 and 2006, aimed primarily at teenagers and young adults. Just Seventeen was a weekly magazine, published in the UK between 1983 and 2004, aimed at teenage girls.

${ }^{5}$ The Sun, the Guardian and the Daily Mail are all daily national newspapers published in the UK.

${ }^{6}$ The X-files was an American television series that aired on Fox from 1993 until 2002. 


\section{References}

Adorno, T. 2001. On the Fetish-Character of Music and the Regression of Listening. In J. Bernstein Ed. The Culture Industry: Selected Essays on Mass Culture. London and New York: Routledge: 270-299.

Anderson, L. 2006. Analytic Auto-ethnography. Journal of Contemporary Ethnography 35 (4): 373-395. http://doi.org/10.1177/0891241605280449

Anderson, T. 2012. Still Kissing their Posters Goodnight: Female Fandom and the Politics of Popular music. Participations Journal of Audience and Reception Studies 9 (2): 239-264. http://www.participations.org/Volume\%209/Issue\%202/15\%20Tonya\%20Ande rson.pdf; Accessed: 1 May 2015.

Anderson, R. and Sharrock, W. 1993. Can Organizations Afford Knowledge? Computer Supported Cooperative Work 1: 143-61. http://doi.org/10.1007/BF00752436

Baker, S. 2013. Teenybop and the Extraordinary Particularities of Mainstream Practice. In S. Baker, A. Bennett and J. Taylor Eds. Redefining Mainstream Popular Music. London and New York: Routledge: 14-24.

Belk, R. W. 1988 Possessions and the Extended Self. Journal of Consumer Research 15 (2): 139-68.

Bennett, A. 2006. Punk's Not Dead: The Continuing Significance of Punk Rock for an Older Generation of Fans. Sociology 40 (2): 219-235. http://doi.org/10.1177/0038038506062030

Booth, R. 2009. Daily Mail Column on Stephen Gately Death Provokes Record Complaints. The Guardian. 16 October. http://www.theguardian.com/music/2009/oct/16/stephen-gately-boyzone; Accessed: 1 May 2015.

Chin, B. and Morimoto, L. 2013. Towards a Theory of Transcultural Fandom. Participations Journal of Audience and Reception Studies 10 (1): 92-108. http://www.participations.org/Volume\%2010/Issue\%201/7\%20Chin\%20\&\%20 Morimoto\%2010.1.pdf; Accessed: 1 May 2015.

Cavicchi, D. 1998. Tramps Like Us: Music and Meaning among Springsteen Fans. New York: Oxford University Press.

Crawford. G. 2004. Consuming Sport: Fans, Sport and Culture. London and New York: Routledge.

DeNora, T. 2000. Music in Everyday Life. Cambridge: Cambridge University Press.

Driessen, S. 2015. Larger than Life: Exploring the Transcultural Fan Practices of the Dutch Backstreet Boys Fandom. Participations Journal of Audience and Reception Studies 12 (2): 180-196. http://www.participations.org/Volume\%2012/Issue\%202/11.pdf; Accessed: 1 May 2015.

Duffett, M. 2013. Understanding Fandom: An Introduction to the Study of Media Fan Culture. London and New York: Bloomsbury Publishing.

Ellis, C. 2004. The Ethnographic I: A Methodological Novel about Autoethnography. Oxford: Rowman Altamira. 
Ellis, C. et al. 2011. Auto-ethnography: An Overview [40 paragraphs]. Forum Qualitative Sozialforschung / Forum: Qualitative Social Research 12 (1): art. 10. http://www.qualitative-research.net; Accessed 24 April 2015.

Green, B. 2016. "I Always Remember That Moment": Peak Music Experiences as Epiphanies. Sociology 50 (2): 333-348.

http://doi.org/10.1177/0038038514565835

Guyotte, K. W. and Sochacka, N. W. 2016. Is This Research? Productive Tensions in Living the (Collaborative) Auto-ethnographic Process. International Journal of Qualitative Methods 15 (1). http://doi.org/10.1177/1609406916631758

Harju, A. (2015) Socially Shared Mourning: Construction and Consumption of Collective Memory. New Review of Hypermedia and Multimedia 21 (1): 123145. http://doi.org/10.1080/13614568.2014.983562

Harrington, C. L. 2010. Autobiographical reasoning in long-term fandom. Journal of Transformative Works and Culture 5. http://dx.doi.org/10.3983/twc.2010.0209

Harrington, C.L. and Bielby, D.D. 2010. A Life Course Perspective on Fandom. International Journal of Cultural Studies, 13 (5): 429-450.

Harrington, C.L., Bielby, D.D. and Bardo, A. R. 2011. Life Course Transitions and the Future of Fandom. International Journal of Cultural Studies 14 (6): 567-590. http://doi.org/10.1177/1367877911419158

Herrmann, A. F. 2013. Daniel Amos and Me. The Popular Culture Studies Journal 1 (1/2): 6-17. http://mpcaaca.org/wp-content/uploads/2013/10/PCSJ-V1-N12Herrmann-Daniel-Amos-and-Me1.pdf; Accessed 24 April 2015.

Hills, M. 2002. Fan Cultures. London and New York: Routledge.

Hodkinson, P. 2013. Spectacular Youth Cultures and Ageing: Beyond Refusing to Grow Up. Sociology Compass 7 (1): 13-22.

http://doi.org/10.1111/soc4.12008

Hodkinson, P. and Bennett, A. 2013. Ageing and Youth Cultures: Music, Style and Identity. London and New York: Berg.

Holt, N. 2003. Representation, Legitimation, and Auto-ethnography: An Autoethnographic Writing Story. International Journal of Qualitative Methods 2 (1): $1-22$.

https://sites.ualberta.ca/ iiqm/backissues/2_1/pdf/holt.pdf; Accessed: 24 April 2015.

Horton, D. and Wohl, R. 1956. Mass Communication and Parasocial Interaction: Observations on Intimacy at a Distance. Psychiatry 19: 215-229. http://dx.doi.org/10.1521/00332747.1956.11023049

Jones, B. 2015 Boyzone, the 'Phonics and Amended-Object Fandom. bethanvjones.wordpress.com.https://bethanvjones.wordpress.com/2015/05/15/ boyzone-the-phonics-and-amended-object-fandom/; Accessed: 15 May 2016.

Lavin, M. 2015. Patti Smith: Aging, Fandom and Libido. Journal of Transformative Works and Culture 20. http://dx.doi.org/10.3983/twc.2015.0658

McCurdy, P. 2010. The King is Dead, Long Live the King: Meditations on Media Events and Michael Jackson. Celebrity Studies 1 (2): 236-238. http://dx.doi.org/10.1080/19392397.2010.482303 
McLean, C. 2006. "I'm Gay and in a Boy Band!". The Guardian 12 November. http://www.theguardian.com/music/2006/nov/12/popandrock10; Accessed 1 May 2015.

Radford, S. K. and Bloch, P. H. 2012. Grief, Commiseration, and Consumption Following the Death of a Celebrity. Journal of Consumer Culture 12 (2): 137155. http://dx.doi.org/10.1177/1469540512446879

Sandvoss, C. 2005. Fans: The Mirror of Consumption. Cambridge: Polity.

Stevenson, N. 2009. Talking to Bowie Fans: Masculinity, Ambivalence and Cultural Citizenship. European Journal of Cultural Studies 12 (1): 79-98. http://doi.org/10.1177/1367549408098706

Sturm, D. 2011. Masculinities, Affect and the (Re)place(ment) of Stardom in Formula One Fan Leisure Practices. Annals of Leisure Research 14 (2-3): 224241. http://doi.org/10.1080/11745398.2011.615717

Vroomen, L. 2002. This Woman's Work: Kate Bush, Female Fans and Practices of Distinction. Phd thesis. Warwick: University of Warwick. http://webcat.warwick.ac.uk/record=b1380298 S9: Accessed: 15 May 2016.

Wall, S. 2008. Easier Said than Done: Writing an Auto-ethnography. International Journal of Qualitative Methods 7 (1): 38-53. http://doi.org/10.1177/160940690800700103

Wicklund, R. A. and Gollwitzer, P. M. 1982. Symbolic Self-completion. Hillsdale, MI: Erlbaum.

Wise, S. 1984. Sexing Elvis. Women's Studies Forum 7 (1): 13-17. http://dx.doi.org/10.1016/0277-5395(84)90077-3

Wise, T. 2012. Introduction: Making Things Whole Again: The Take That Reunion. Popular Music History 7 (2): 117-120. http://doi.org/10.1558/pomh.v7i2.117

Williams, R. 2011. "This Is the Night TV Died": Television Post-Object Fandom and the Demise of The West Wing. Popular Communication 9 (4): 266-279. http://doi.org/10.1080/15405702.2011.605311 2015. Post-Object Fandom Television, Identity and Self-narrative. New York: Bloomsbury. 